\title{
Endocrine changes and luteal morphology during pregnancy in muskoxen (Ovibos moschatus)
}

\author{
J. E. Rowell ${ }^{1 *}$, R. A. Pierson ${ }^{2}$ and P. F. Flood ${ }^{1}$ \\ ${ }^{1}$ Department of Veterinary Anatomy, Western College of Veterinary Medicine, University of \\ Saskatchewan, Saskatoon, Saskatchewan S7N OWo Canada; and ${ }^{2}$ Reproductive Biology Unit, \\ Department of Obstetrics and Gynaecology, University of Saskatchewan, Saskatoon, \\ Saskatchewan S7N OXO Canada
}

\begin{abstract}
Progesterone, oestradiol and oestrone were measured in plasma from four captive muskoxen during three consecutive pregnancies (1983-1984, 1984-1985 and 1985-1986). Jugular blood samples were collected weekly (1983) or on an alternating 3:4 day schedule (19841986) during the first 12-15 weeks and last 6-10 weeks of pregnancy. Sampling during mid-pregnancy was at intervals of 2 weeks (1983 and 1985) or 1 week (1986). Duration of gestation was about 34 weeks ( $235 \pm 4$ (SD) days $(n=10)$, range $230-242$ days). Progesterone remained at concentrations similar to those found during the luteal phase of the oestrous cycle for the first $10-12$ weeks (mean \pm SEM $1.6 \pm 0.1 \mathrm{ng} \mathrm{ml}^{-1}$ ) after which it rose to a peak (mean $5.5 \pm 0.65 \mathrm{ng} \mathrm{ml}^{-1}$ ) between weeks 12 and 20 . In all ten pregnancies progesterone concentrations declined dramatically between weeks 20 and 22 to luteal phase values where they remained until parturition. The decline was accompanied by an increase in oestradiol and oestrone concentrations which reached mean peak values of $199.23 \pm 87.23 \mathrm{pg} \mathrm{ml}^{-1}$ and $980.48 \pm 203.91 \mathrm{pg} \mathrm{ml}^{-1}$, respectively. Corpora lutea collected from wild muskoxen between 45 and 80 days gestation all showed histological evidence of regression, while corpora lutea from mid-gestation (112-125 days) were in advanced stages of involution. Repeated ovarian ultrasonography of captive muskoxen during the first 100 days of pregnancy confirmed these findings. The unusual, early regression of the corpus luteum of pregnancy indicates that progesterone and oestrogen of mid- and late pregnancy are probably of placental origin. The temporal relationship between the concentrations of these hormones during late pregnancy differs from those of domestic species and is apparently unique among ruminants.
\end{abstract}

\section{Introduction}

Similarities in reproductive endocrinology and anatomy are among the many common features shared by muskoxen, sheep and goats, all members of the subfamily, Caprinae (Simpson, 1945). The uterus, ovaries and placenta of the muskox closely resemble those of sheep and goats (Rowell et al., 1987) as do duration of oestrous cycles and endocrine changes during the oestrous cycle (Rowell and Flood, 1988). One notable difference between muskoxen and goats and sheep is the lack of a grossly visible corpus luteum in muskox ovaries $3-6$ weeks before parturition. At this late stage of pregnancy only a small scar can be detected histologically (Rowell et al., 1987).

There is a major difference between goats and sheep in the source of progesterone during pregnancy (Flint et al., 1983). Goats depend on luteal progesterone throughout gestation (Meites et al., 1951), whereas sheep require luteal progesterone only for the first 50-60 days of pregnancy (Casida and Warwick, 1945). Muskoxen are therefore similar to sheep in

*Present address: Institute of Arctic Biology, University of Alaska Fairbanks, Fairbanks AK 99775-0180, USA.

Received 23 June 1992. their ability to support a fetus during the later stages of gestation in the absence of a corpus luteum. However, complete disappearance of the corpus luteum in the muskox makes this species most unusual and suggests that its endocrine control of pregnancy differs from that of sheep.

Existing reports of peripheral progesterone concentrations in pregnant muskoxen are all derived from single samples taken from captive muskoxen in Norway, as a means of pregnancy detection (Nilssen et al., 1984) or from wild muskoxen in the Canadian Arctic immediately after death (Rowell, 1980; Tessaro et al., 1984). The purpose of this study was to describe the patterns of reproductive steroids in peripheral blood and the changes occurring in the corpus luteum during pregnancy in muskoxen.

\section{Materials and Methods}

\section{Captive animals}

Female muskoxen maintained at the University of Saskatchewan were used for endocrine and morphological studies between 
1983 and 1989 . The cows were 1.5 years old at the beginning of the study and were kept together in outdoor pens with nonpregnant females, bulls and castrates. They were fed supplemented oat pellets and had free access to brome-alfalfa hay and water. The muskoxen had been bottle raised and were fully accustomed to handling and restraint so that twice weekly jugular venepuncture or transrectal ultrasonography caused minimal observable stress (Rowell, 1991).

\section{Sample collection}

Four pregnant females were sampled by jugular venepuncture throughout their first pregnancy and three of the four cows were sampled during their next two pregnancies. During early and late pregnancy samples were taken once (1983) or twice (1984, 1985) a week. Bimonthly $(1983)$ or weekly $(1984,1985)$ samples were collected during mid-pregnancy. The ten pregnancies included in this study were all carried to term.

Cows were observed for signs of oestrus and mating (Rowell and Flood, 1988) and the day of mating was designated as day 0. Over the three breeding seasons the earliest fertile mating occurred on 24 September and the latest on 15 November. The endocrine data for all pregnancies have been normalized to day 0 .

The samples (approximately $10 \mathrm{ml}$ ) were collected between 09:00 and 12:00 $\mathrm{h}$ in heparinized evacuated tubes (Vacutainer: Becton-Dickinson, Rutherford, NJ), refrigerated immediately and centrifuged at $1200 \mathrm{~g}$ for $10 \mathrm{~min}$ within $1 \mathrm{~h}$ of collection to optimize progesterone preservation (Rowell and Flood, 1987). Plasma was stored at $-22^{\circ} \mathrm{C}$ until assayed.

\section{Assays}

Progesterone concentrations were determined in duplicate samples using a double antibody method and ${ }^{125}$ I-labelled progesterone (Rawlings et al., 1984; Rowell and Flood, 1988). Coefficients of variation were calculated from a high (about $2.5 \mathrm{ng} \mathrm{ml}^{-1}$ ) and a low (about $1.3 \mathrm{ng} \mathrm{ml}^{-1}$ ) reference pool of sheep plasma. The mean intra-assay coefficients of variation were 7.4 and $9.8 \%$ for high and low references, respectively. The interassay coefficient of variation was 11.7 (high) and $14.6 \%$ (low).

Oestradiol, from six of the ten pregnancies, was measured in $0.5 \mathrm{ml}$ aliquots of muskox plasma extracted in ethyl ether and assayed using $\left[{ }^{3} \mathrm{H}\right]$ oestradiol (Joseph et al., 1992). Standards were extracted from charcoal-stripped serum (CSS) from castrate muskox, eliminating the need for an extraction calculation. The blank, also CSS, was below assay sensitivity. The range of the standard curve was $0.5-200 \mathrm{pg}$ and the sensitivity was I pg $\mathrm{ml}^{-1}$. Intra-assay coefficients of variation, determined from low $(2 \mathrm{pg})$ and high (10 pg) references were 6.8 and $8.2 \%$, respectively, whereas interassay coefficients of variation were 16.7 (low) and 5.2\% (high).

Oestrone from three of the ten pregnancies was similarly assayed using $\left[{ }^{3} \mathrm{H}\right]$ oestrone: standards and $1 \mathrm{ml}$ aliquots of muskox plasma were extracted with ethyl ether from CSS. The antiserum (raised in sheep against 1,3,5,(10)-oestratriene-3ol-6,17-dione-6-carboxy-methyloxime: BSA, (Steraloids E2056; Wilton, New Hampshire) had the following crossreactions: oestradiol, $0.4 \%$ and $17 \alpha$-oestradiol, $0.3 \%$; oestriol, cortisol, cholesterol, cortisone, corticosterone, testosterone, dihydrotestosterone, androstene-3,17-dione, progesterone and pregnenolone all crossreacted $<0.01 \%$. The blank, also CSS, did not differ from zero. The standard curve was from 10 to $500 \mathrm{pg} \mathrm{ml}^{-1}$ and assay sensitivity was $5 \mathrm{pg} \mathrm{ml}^{-1}$. The intraassay coefficients of variation for a high (about $50 \mathrm{pg} \mathrm{ml}^{-1}$ ) and a low (about $20 \mathrm{pg} \mathrm{ml}^{-1}$ ) concentration reference ewe plasma were 10.1 and $8.4 \%$ and interassay coefficients of variation were 7.5 and $12.8 \%$, respectively.

\section{Histology of ovaries from pregnant, wild muskoxen}

Ovaries were collected during muskox harvests on Banks Island on 11-13 December 1985 ( $n=19), 4$ November 1987 $(n=11)$ and 22-23 September $1988(n=12)$. The ovaries were bisected longitudinally and fixed in $10 \%$ buffered formalin. After fixation, measurements of macroscopically visible corpora lutea were made by taking two diameters at right angles. Fetal weights, fetal transcranial diameter (measured just behind the orbits with callipers) or crown-rump lengths (embryos) were used to estimate the stage of gestation. Ovaries collected in December 1985 were not accompanied by a fetus from the same pregnant female and the approximate stage of gestation could only be inferred by comparison with weights of 13 fetuses collected from other females on the same occasion. Fetal age was estimated using the formula of Huggett and Widdas (1951), comparison with cattle and sheep fetal development and crown-rump measurements (Evans and Sack, 1973), and a comparison of transcranial measurements with those collected by ultrasonography from captive muskoxen (Pharr and Rowell, 1989).

After fixation, ovaries were embedded in paraffin wax, sectioned at 5-6 $\mu \mathrm{m}$ and stained with haematoxylin and eosin or Gomori's trichrome stain. The ovaries were not serially sectioned and no measurements or volumes were calculated from sectioned tissues.

\section{Transrectal ultrasonography}

The genital tracts of four tame muskoxen were examined at regular intervals by ultrasonography in three successive breeding seasons (1988, 1989, 1990). The animals were lightly sedated with $60 \mathrm{mg}$ acepromazine (Atravet Granules, Ayerst) given orally 30-45 min before examination, and restrained in a headgate immediately before scanning. In 1988, examinations were performed weekly from about day 50 of gestation until the corpus luteum could no longer be detected. In 1989, the same animals were examined at intervals of 14 days from the time of conception until the corpus luteum could no longer be identified. In 1990, additional data were collected during very early pregnancy.

Scans were performed with a Tokyo Keiki LS-200 instrument equipped with a $5 \mathrm{MHz}$ intrarectal transducer (Products Group International, Boulder, CO) $(1988,1989)$ or an Aloka DS-210 instrument with a $7.5 \mathrm{MHz}$ intrarectal transducer (1990). Upon insertion of the probe into the rectum, the cervix was located and the transducer moved along the dorsal surface of the reproductive tract to facilitate orientation. The uterine horns were examined in longitudinal and oblique planes; the transducer was 
then directed laterally to examine the ovaries. The conceptus (Kastelic et al., 1988) and the ovaries (Pierson et al., 1988) were evaluated as described previously in cattle. When a corpus luteum was identified, the image was frozen when the luteal dimensions appeared maximal. The greatest linear dimension and the greatest dimension perpendicular to it were recorded. Luteal volumes were calculated on the assumption that the corpus luteum was approximately ellipsoidal (volume $=$ $\frac{4}{3} \pi a b c$ where $a, b$ and $c$ are the radii) and that the unknown axis was the mean of the measured axes.

\section{Results}

Duration of gestation was $235 \pm 4$ days (mean \pm SD), range 230-242 days, an average of 34 weeks. Of the ten pregnancies, eight resulted in normal deliveries with healthy calves, one (presented caudally with flexed hocks) was delivered with assistance and one was a stillbirth. Examination of afterbirths from all pregnancies revealed placentitis in the intercotyledonary regions that ranged in severity from a trace $(\leqslant 1 \%$ of tissue affected, $n=3$ ) to mild ( $1-10 \%$ of tissue affected, $n=5$ ) to moderate (10-50\% of tissue affected, $n=2$ ) (Blake and Rowell, 1989). The placentae from the caudal presentation and the stillbirth were the most severely affected.

\section{Hormones}

During the first 10-12 weeks of gestation plasma progesterone remained at peak luteal phase concentrations (mean \pm SEM $1.6 \pm 0.1 \mathrm{ng} \mathrm{ml}^{-1}$ ). Progesterone concentrations began to rise between weeks $10-12$ reaching peak concentrations (mean $5.5 \pm 0.7 \mathrm{ng} \mathrm{ml}^{-1}$ ) by weeks $16-20$. In all ten pregnancies, progesterone concentrations declined dramatically between weeks 20 and 22 (mean $2.0 \pm 0.8 \mathrm{ng} \mathrm{ml}^{-1}$ ) (Fig. Ia, b). These concentrations were similar to those of early pregnancy and were maintained until just before parturition. A slight increase of $1-2 \mathrm{ng} \mathrm{ml}^{-1}$ was evident in some individuals 2 weeks before parturition. In all animals the decline occurred at the same stage of gestation regardless of whether conception occurred in September or November.

Both oestradiol and oestrone remained low for the first 20 weeks. However, as progesterone concentrations declined, circulating concentrations of both oestrogens increased to peak values (mean $980 \pm 203 \mathrm{pg} \mathrm{ml}^{-1}$ for oestrone and a mean of $199 \pm 87 \mathrm{pg} \mathrm{ml}^{-1}$ for oestradiol). There were large fluctuations in the concentrations of both oestrogens during the last 5-6 weeks of pregnancy (Fig. 1a).

\section{Morphology of the corpus luteum}

On the basis of fetal development, tissues collected in September were estimated at 4-6 weeks; the November collection, 10-12 weeks and the December collection 16-18 weeks gestation.

Fixed corpora lutea from 4-6 weeks gestation were yellow in colour and almost circular in cross-section with gross, mean dimensions of $1.1 \mathrm{~cm} \times 1.2 \mathrm{~cm}$. Only four of twelve specimens had remnants of a 'crown' and caused an obvious swelling within the ovary (Fig. 2). Large luteal cells with round, vesicular

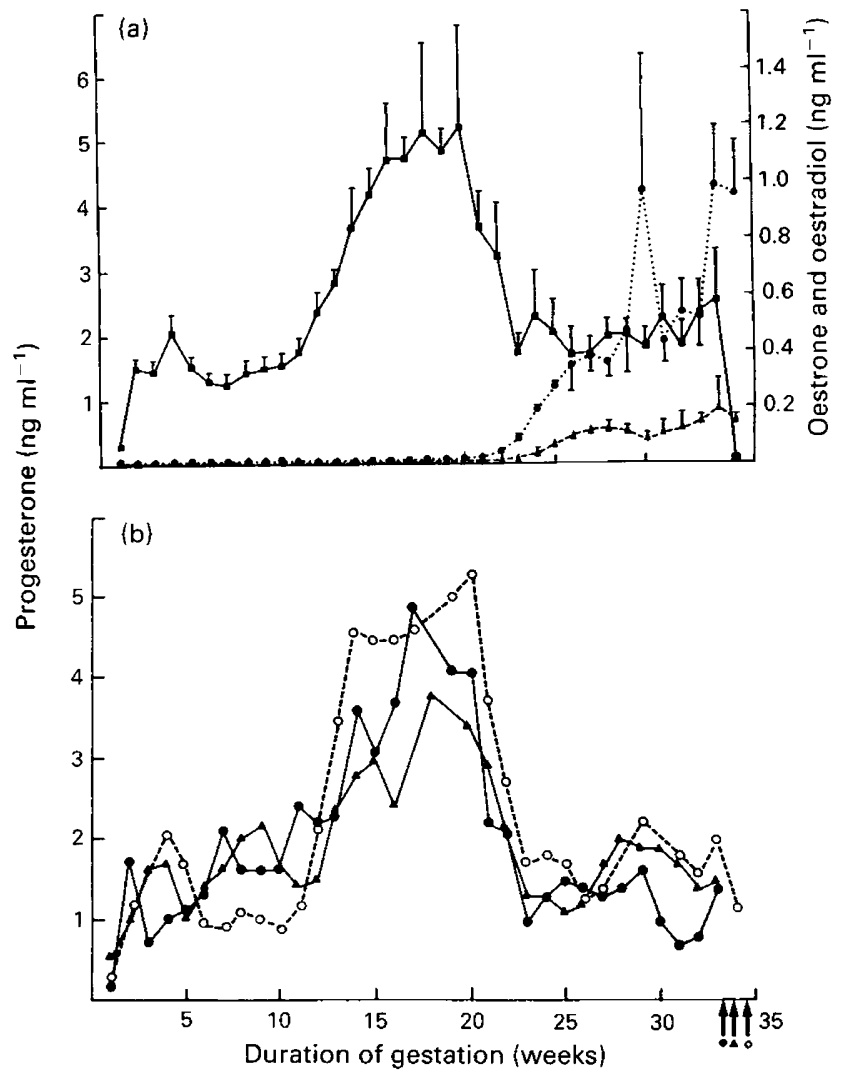

Fig. 1. (a) Plasma progesterone ( $\boldsymbol{\square}$ ) (mean \pm SEM, $n=10$ ), oestradiol ( $\Delta$ ) (mean \pm SEM, $n=6$ ) and oestrone $(\mathbf{O})$ (mean \pm SEM, $n=3$ ) concentrations during pregnancy in captive muskoxen. The data were normalized to the day of mating but parturition dates differed. The last point on the progesterone curve ( 35 weeks) is a mean of postpartum samples from all pregnancies. (b) The pattern of progesterone concentrations in three representative, pregnant muskoxen. Although there were differences in individual values, the progesterone decline at 20 weeks was clearly evident in all cases. Blood sampling stopped 3-4 days before parturition. The times of parturition are indicated by the arrows.

nuclei and prominent nucleoli were the most obvious type of cell. The remainder of the tissue comprised small luteal cells, connective tissue and vascular elements. The corpora lutea had a connective tissue core with strands of connective tissue radiating into the parenchyma. Although the majority of the cells appeared healthy, cell death and intravascular cellular debris were evident (Fig. 3a, b). Lymphocytes, neutrophils and plasma cells were found throughout the tissue.

At $10-12$ weeks gestation the corpora lutea were macroscopically smaller $(0.82 \mathrm{~cm} \times 0.99 \mathrm{~cm})$ and none protruded from the surface of the ovary. Luteal size was variable and did not correlate well with estimated fetal age (Fig. 2). Connective tissue cores are evident on gross examination. Apparently healthy large luteal cells were still visible in all corpora lutea but the cells were less distinct. Marked eosinophilia of luteal cell cytoplasm, karyorrhexis and pyknosis were evident (Fig. 3c). Intercellular connective tissue had increased and pigment accumulation was apparent. Many capillaries contained cellular debris and thick walled vessels were numerous. Lymphocytic invasion from the periphery was noted in addition to clusters of lymphocytes within the corpus luteum. The cellular changes 

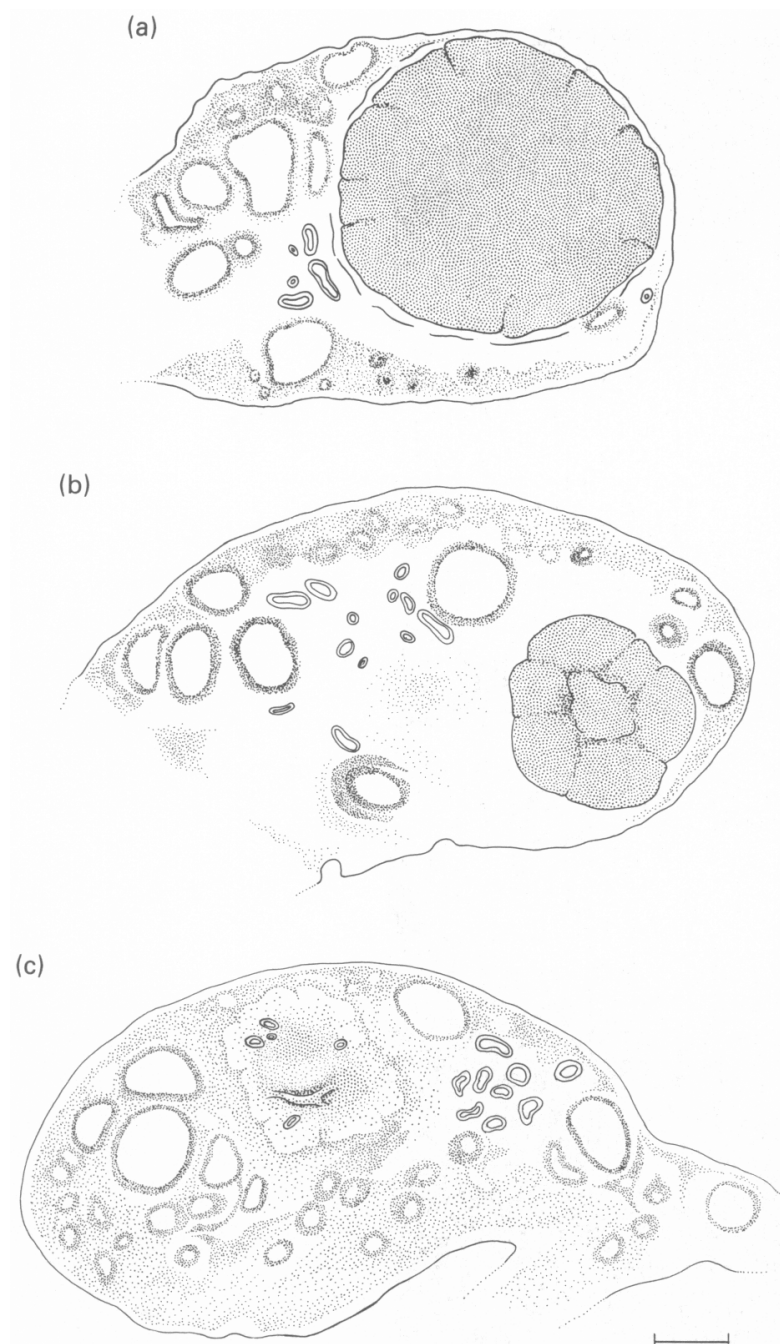

Fig. 2. Drawings of representative sections of muskox ovaries at (a) 46 , (b) 10-13, (c) 16-18 weeks gestation. The loss in size and definition of the corpus luteum is evident. $\mathrm{Bar}=0.5 \mathrm{~cm}$.

were patchy in some corpora lutea and pockets of apparently healthy tissue could be found indicating that degeneration had not occurred uniformly.

Only eight of $19(42 \%)$ animals killed at 16-18 weeks gestation had a grossly visible corpus luteum on bisection of the ovaries (Fig. 2). Under light microscopy all corpora lutea stained intensely for connective tissue with Gomori's trichrome and neither large nor small luteal cells could be found (Fig. 3d).

Estimation of luteal volume by transrectal ultrasonography revealed that luteal regression was a gradual process that began during, or before, week 8 of pregnancy and was complete by week 15 (Fig. 4). Thus, regression started well before the sharp mid-pregnancy rise in peripheral progesterone concentration became evident.

\section{Discussion}

Pregnancy in the muskox has at least two unusual features. First, histological examination of ovaries from wild muskox cows and repeated ovarian ultrasonography of tame muskoxen has shown that the corpus luteum of pregnancy shrinks steadily during early gestation and is reduced to a scar devoid of luteal cells by the sixteenth week of pregnancy. Second, at 20-22 weeks gestation, two thirds of the total gestation period, progesterone concentrations fall sharply from their midpregnancy maximum to concentrations similar to those seen during the luteal phase of the oestrous cycle (Rowell and Flood, 1988).

Complete regression of the corpus luteum during pregnancy is known to occur in horses (Squires et al., 1974), but has not been reported in other species. Of the ruminants that have been studied in any detail, cattle, which produce both placental and luteal progesterone (Dobson and Kamonpatana, 1986), show little change in luteal volume during pregnancy, although the number of luteal cells is significantly reduced near term (Shemesh, 1990). Goats depend completely on a functional corpus luteum throughout pregnancy (Thorburn and Schneider, 1972). The limited information on cervids indicates that red deer rely on luteal progesterone throughout pregnancy (Kelly et al., 1982) and white-tail deer exhibit a relatively constant progesterone pattern during pregnancy similar to those of goats and cattle (Plotka et al., 1977). Domestic sheep do not require luteal progesterone during the latter half of gestation (Sarda et al., 1973). However, the sheep corpus luteum shows only slight shrinkage 2-3 weeks before term (O'Shea and McCoy, 1988) and active luteal cells persist into the postpartum period (O'Shea and Wright, 1985).

The cause of early regression of the muskox corpus luteum of pregnancy is unknown, but it is clear from both the progesterone data and morphological studies that the corpus luteum persists for longer in pregnant than in nonpregnant muskoxen (Rowell and Flood, 1988). The normal ruminant antiluteolytic mechanisms for the establishment of pregnancy (Roberts, 1989) therefore appear to operate in this species. Subsequent luteal regression could stem from a lack of luteotrophic support or through the action of a luteolytic agent.

The complete regression of the only corpus luteum of pregnancy implicates the placenta as the primary site of progesterone production for the remainder of pregnancy. The contribution of adrenal progesterone was not investigated in muskoxen. The stimulated adrenal cortex can produce significant amounts of progesterone in cervids (Jopson et al, 1990), but in domestic sheep, progesterone production by the unstimulated adrenal cortex is minimal (Harrison and Heap, 1978).

The shape of the progesterone profile of pregnancy differs among ruminants, although all show a decline immediately before parturition. In cattle (Stabenfeldt $e t$ al., 1970; Dobson and Kamonpatana, 1986) progesterone concentrations rise little, if at all, above those of the luteal phase; in goats (Thorburn and Schneider, 1972) there is a slight increase in progesterone in the last two-thirds of pregnancy; and in all the species of sheep examined - domestic sheep (Bassett et al., 1969; Stabenfeldt et al., 1972; Tsang, 1978); bighom sheep (Whitehead and McEwan, 1980); Barbary sheep (Hamon and Heap, 1990) - progesterone concentrations rise well above those of the luteal phase in the second half of gestation and tend to peak shortly before term. The muskox progesterone profile is unique among these and the marked decline in concentrations that occurs at 20-22 weeks gestation has no counterpart in other species studied to date. 

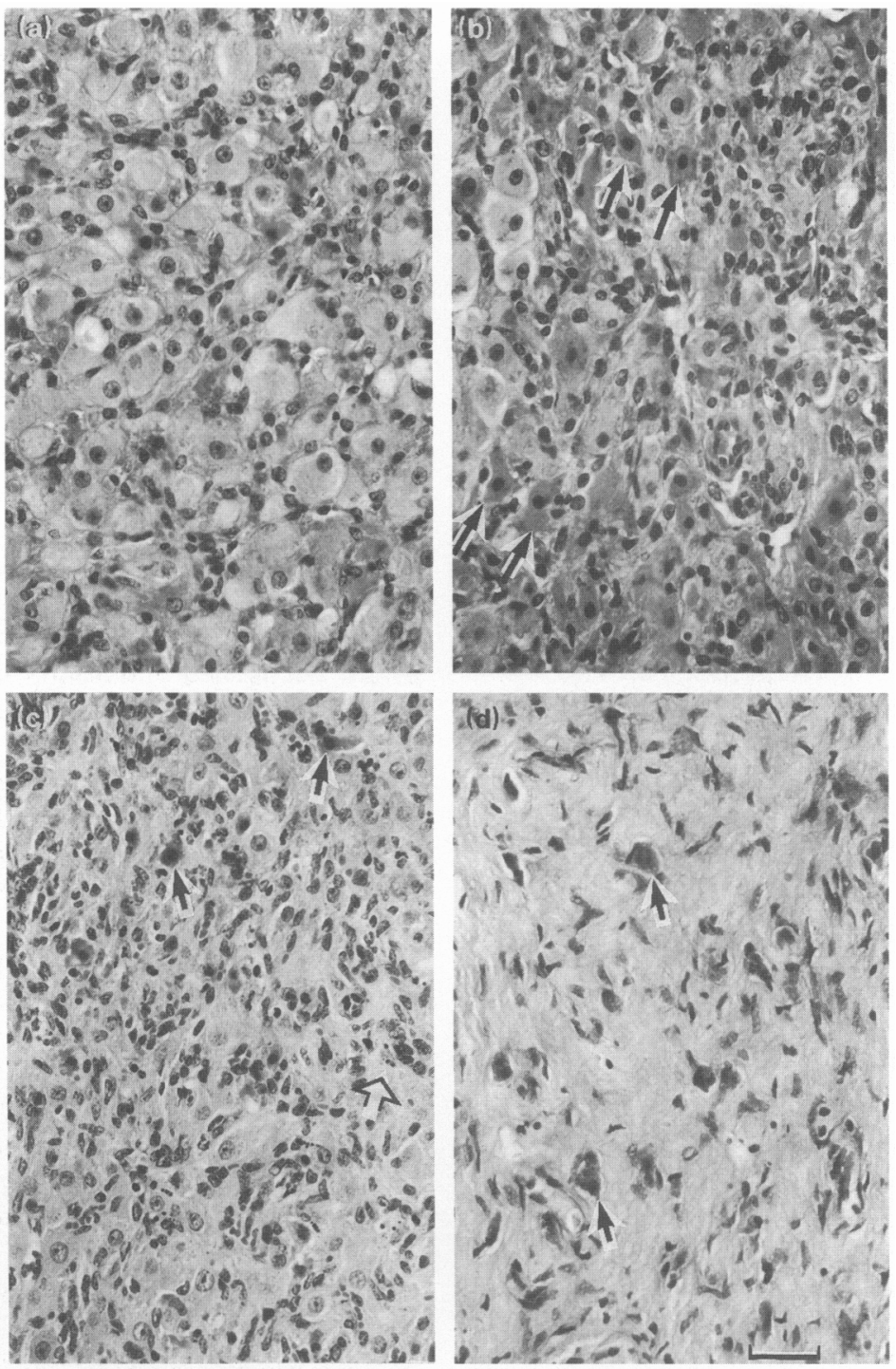

Fig. 3. Representative photomicrographs of the corpus luteum of pregnancy at 3 stages of gestation. Stained with haematoxylin and eosin. Bar $=35 \mu \mathrm{m}$. (a and b) 4-6 weeks gestation. Large luteal cells with prominent nucleoli predominated (a), although some evidence of cell death was found in all corpora lutea at this stage of gestation (arrows, b). (c) 10-12 weeks gestation. Although apparently healthy large luteal cells could still be found, there were few, cell definition was being lost, pyknotic nuclei (black arrow) and karyorrhexis (open arrow) were common features. (d) 16-18 weeks gestation. No luteal cells could be found and the luteal scar consisted entirely of connective tissue and pigment laden macrophages (arrows).

The decline in progesterone concentration does not seem to be homologous with the preparturient shift from progesterone to oestrogen production that occurs in sheep and cattle. In muskoxen the decline occurred 10-12 weeks before term and it is unlikely that it would be initiated by a rise in fetal corticosteroids at this stage of gestation. There is limited evidence that fecal progestagens are abundant in late pregnant muskoxen (Desaulniers et al., 1989). It is, therefore, possible that the sudden reduction in circulating progesterone is caused by an increase in excretion rate or a switch to the formation of a metabolite not recognized by our plasma assay. A detailed description of hormonal changes immediately before parturition is not possible with the sampling schedule used in this study.

Progesterone concentrations ranging between 3.3 and $11.5 \mathrm{ng} \mathrm{ml}^{-1}$ were found in pregnant, captive muskoxen in Norway. On the basis of subsequent calving dates, the blood samples were probably taken at about the time of the fall in progesterone, thus accounting for the large variation observed (Nilssen et al., 1984). Blood samples collected from wild muskoxen in the Canadian Arctic at an estimated 4-6 weeks before calving all had progesterone concentrations consistent with our present findings (Rowell, 1980). 


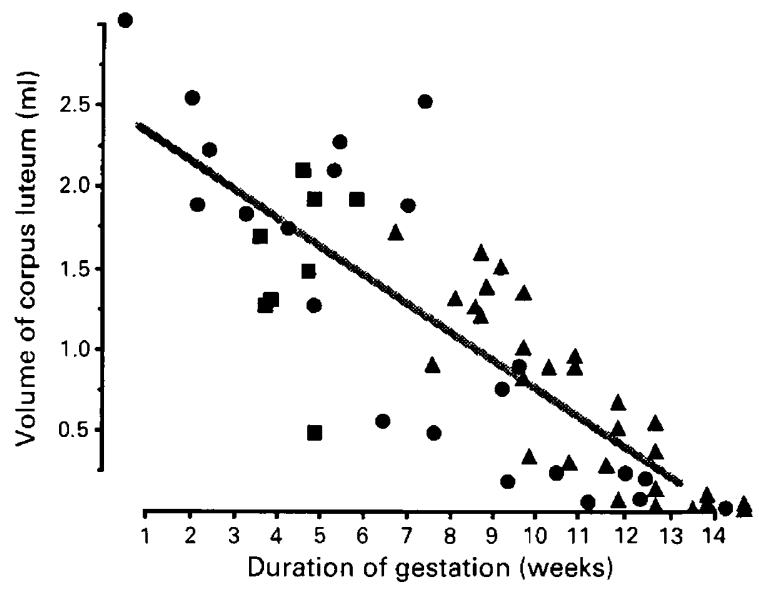

Fig. 4. The relationship between luteal volume and stage of gestation in muskoxen determined by transrectal ultrasonography. The data were accumulated over three breeding seasons (1988-1989, $\boldsymbol{\Delta}$; 1989$1990,0 ; 1990-1991, \square)$. The line drawn through the points is a simple regression $\left(R^{2}=0.67, P<0.0001\right)$.

Oestrogen concentrations rose in the latter third of pregnancy when progesterone was low. This changing hormonal relationship may be partially attributed to conversion of progesterone to oestrogens. We did not measure oestrone sulfate, although evidence from sheep indicates that sulfate concentrations may greatly exceed those of unconjugated oestrogens, providing an abundant substrate pool for oestrogen production (Tsang, 1978). If this is also true for the muskox then the oestrogen rise in the last few weeks of gestation need not be the immediate result of progesterone metabolism.

The gestation of 235 days ( 34 weeks) reported here was shorter than the 250 days reported by Alendal (1971) by approximately the duration of one oestrous cycle. This observation was made on free ranging animals and it is possible that they failed to conceive at the observed mating.

Eight of the ten pregnancies for which we have presented endocrine data ended in the normal birth of a healthy calf but in all cases a placentitis of unidentified aetiology was found (Blake and Rowell, 1989). In the normal deliveries the lesions were minimal but in two cases, one malpresentation and one stillbirth, they were extensive. In spite of this, the hormone concentrations and duration of gestation were similar in all the pregnancies and it seems unlikely that the placental lesions have influenced these results.

The close phylogenetic relationship between sheep, goats and muskoxen (Rowell, 1990) and the numerous similarities in their reproductive anatomy and physiology (Rowell et al., 1987; Rowell and Flood, 1988) make the subtly different features reported here all the more intriguing. The fact that muskoxen are also the only member of the Bovidae to have evolved in the extremes of an arctic environment invites speculation on the possible selective advantages that may be conferred on pregnant muskoxen by the unique, early luteal regression and the unusual, triphasic progesterone profile.

This study was supported by the National Sciences and Engineering Research Council Operating Grant A2759 and Infrastructure Grant
A2793. Samples were assayed by Reproductive Endocrine Assay Systems, Reproductive Endocrine Laboratory, Western College of Veterinary Medicine, Saskatoon. The field collections were supported by the Northern Scientific Training Grants Program, Department of Indian Affairs and Northern Development, and by the Department of Renewable Resources, Government of the Northwest Territories, with special thanks to Bruce McLean for his assistance and support during the collections. Colleen Stevens provided invaluable assistance and dedicated care of the captive muskoxen; care later continued by $\mathrm{E}$. Lammerding. We thank S. Tedesco and J. Adamczewski for their comments and suggestions and J. Deubner for preparation of Fig. 2.

\section{References}

Alendal E (1971) Early sexual maturity and high fecundity in wild muskoxen in Norway Fauna 24 96-100

Bassett JM, Oxborrow TJ, Smith ID and Thorburn TJ (1969) Concentration of progesterone in the peripheral plasma of the pregnant ewe Journal of Endocrinology 45 449-457

Blake JE and Rowell JE (1989) Placentitis in a herd of captive muskoxen. In Proceedings of the Second International Muskox Symposium, Saskatoon, Saskatchewan 1987 pp A59-A60 Ed. PF Flood. National Research Council of Canada, Ottawa

Casida LE and Warwick EJ (1945) The necessity of the corpus luteum for the maintenance of pregnancy in the ewe Journal of Animal Science 4 34-36

Desaulniers D, Goff AK, Betteridge KJ, Rowell JE and Flood PF (1989) Reproductive hormone concentrations in faeces during the oestrous cycle and pregnancy in cattle (Bos taurus) and muskoxen (Ovibos moschatus) Canadian Journal of Zoology 67 1148-1154

Dobson $\mathrm{H}$ and Kamonpatana M (1986) A review of female cattle reproduction with special reference to a comparison between buffaloes, cows and zebu journal of Reproduction and Fertility 77 1-36

Evans HE and Sack WO (1973) Prenatal development of domestic and laboratory mammals: growth curves, external features and selected references Anatomy Histology Embryology 2 11-45

Flint APF, Burton RD and Heap RB (1983) Sources of progesterone during gestation in Barbary sheep (Ammotragus lervia) Journal of Endocrinology $\mathbf{9 8}$ 283-288

Hamon MH and Heap RB (1990) Progesterone and oestrogen in plasma of Barbary sheep (Aoudad, Ammotragus lervis) compared with those of domestic sheep and goats during pregnancy Joumal of Reproduction and Fertility 90 $207-211$

Harrison FA and Heap RB (1978) Progesterone secretion during pregnancy in sheep with an autotransplanted adrenal and an autotransplanted ovary Joumal of Reproduction and Fertility 54 153-157

Huggett AStG and Widdas WF (1951) The relationship between mammalian foetal weight and conception age Journal of Physiology 114 306-317

Jopson NB, Fisher MW and Suttie JM (1990) Plasma progesterone concentrations in cycling and in ovariectomised red deer hinds: the effect of progesterone supplementation and adrenal stimulation Animal Reproduction Science 23 61-73

Joseph IBJK, Currie WD and Rawlings NC (1992) Effects of time after ovariectomy, season and oestradiol on luteinizing hormone and folliclestimulating hormone secretion in ovariectomized ewes Journal of Reproduction and Fertility 94 511-523

Kastelic JP, Curran S, Pierson RA and Ginther OJ (1988) Ultrasonic evaluation of the bovine conceptus Theriogenology 29 39-54

Kelly RW, McNatty KP, Moore GH, Ross D and Gibb M (1982) Plasma concentrations of $\mathrm{LH}$, prolactin, oestradiol and progesterone in female red deer (Cervus elaphus) during pregnancy Journal of Reproduction and Fertility 64 475-483

Meites J, Webster HD, Young FW, Thorp F and Hatch RN (1951) Effects of corpora lutea removal and replacement with progesterone on pregnancy in goats Journal of Animal Science 10 411-416

Nilssen KJ, Mathiesen SD, Solberg E and Blix AS (1984) Use of progesterone for diagnosis of pregnancy in muskoxen Biological Papers of the University of Alaska, Special Report 4186

O'Shea JD and McCoy K (1988) Weight, composition, mitosis, cell death and content of progesterone and DNA in the corpus luteum of pregnancy in the ewe Journal of Reproduction and Fertility 83 107-117 
O'Shea JD and Wright PJ (1985) Regression of the corpus luteum of pregnancy following parturition in the ewe Acta Anatomica 122 69-76

Pharr JW and Rowell JE (1989) Determination of fetal growth in the muskox by trans-abdominal ultrasonography. In Proceedings of the Second International Muskox Symposium Saskatoon, Saskatchewan pp A53-A54 Ed. PF Flood. National Research Council of Canada, Ottawa

Pierson RA, Kastelic JP and Ginther OJ (1988) Basic principles and techniques for transrectal ultrasonography in cattle and horses Theriogenology 29 3-20

Plotka ED, Seal US, Verme LJ and Ozogoa JJ (1977) Reproductive steroids in the white-tailed deer (Odocoileus virginianus borealis). II Progesterone and estrogen levels in peripheral plasma during pregnancy Biology of Reproduction 17 78-83

Rawlings NC, Jeffcoate IA and Reiger DL (1984) The influence of estradiol-17 $\beta$ and progesterone on peripheral serum concentrations of luteinizing hormone and follicle stimulating hormone in the ovariectomized ewe Theriogenology 22 473-488

Roberts MR (1989) Conceptus interferons and maternal recognition of pregnancy Biology of Reproduction 40 449-452

Rowell JE (1980) A Preliminary Study of the Anatomy of the Female Muskox (Ovibos moschatus) pp 190. MSc Thesis, University of Ottawa, Ottawa

Rowell JE (1990) The muskox. In Intemational Studbook for Muskoxen (Ovibos moschatus) Ed. B Holst. Copenhagen Zoo, Copenhagen

Rowell JE (1991) Reproductive Biology and Endocrinology in Captive Muskoxen pp 203. PhD Thesis, University of Saskatchewan, Saskatoon

Rowell J and Flood PF (1987) Changes in muskox blood progesterone concentration between collection and centrifugation Journal of Wildlife Management 51 901-903

Rowell JE and Flood PF (1988) Progesterone, oestradiol-17 $\beta$ and LH during the oestrous cycle of muskoxen (Ovibos moschatus) Journal of Reproduction and Fertility 84 117-122
Rowell J, Betteridge KJ, Randall GCB and Fenwick JC (1987) Anatomy of the reproductive tract of the female muskox (Ovibos moschatus) Joumal of Reproduction and Fertility 80 431-444

Sarda IR, Robertson HA and Smeaton TC (1973) Sequential changes in plasma progesterone levels in the ewe during the estrous cycle, and during pregnancy in intact and ovariectomized sheep Canadian Journal of Animal Science 53 25-34

Shemesh $\mathbf{M}$ (1990) Production and regulation of progesterone in bovine corpus luteum and placenta in mid and late gestation: a personal review Reproduction Fertility and Development 2 129-135

Simpson GG (1945) The principles of classification and a classification of mammals Bulletin of the American Museum of Natural History 85 1-350

Stabenfeldt GH, Osburn BI and Ewing LL (1970) Peripheral plasma progesterone levels in the cow during pregnancy and parturition American Journal of Physiology 218 571-575

Stabenfeldt GH, Drost M and Franti CE (1972) Peripheral plasma progesterone levels in the ewe during pregnancy and parturition Endocrinology 90 144-150

Squires EL, Garcia MC and Ginther OJ (1974) Effect of pregnancy and hysterectomy on the ovaries of pony mares Journal of Animal Science 38 823-834

Tessaro S, Rowell JE, Cawthorn R and Latour P (1984) Banks Island Muskox Harvest, 1982 Biological Papers of the University of Alaska, Special Report 4 $177-180$

Thorburn GD and Schneider W (1972) The progesterone concentrations in the plasma of the goat during the oestrous cycle and pregnancy Journal of Endocrinology 52 23-36

Tsang CPW (1978) Plasma levels of estrone sulfate, free estrogens and progesterone in the pregnant ewe throughout gestation Theriogenology 10 97-110

Whitehead PE and McEwan EH (1980) Progesterone levels in the peripheral plasma of rocky mountain Bighorn ewes (Ovis canadensis) during the estrous cycle and pregnancy Canadian journal of Zoology 58 1105-1108 